\title{
Subakut Tiroiditli Olguların Retrospektif Analizi
}

Retrospective Analysis of Cases With Subacute Thyroiditis Ziynet Alphan Üç ${ }^{1}$ (D) Canan Akkuş ${ }^{\text {(D) , Cevdet Duran }}{ }^{1}$ (iD

1 Endokrinoloji ve Metabolizma Hastalıkları Bilim Dalı, İç Hastalıkları Anabilim Dalı, Uşak Üniversitesi Tıp Fakültesi Uşak/Türkiye 2 İç Hastalıkları Kliniği, Uşak Eğitim ve Araştırma Hastanesi Uşak/Türkiye

\section{ÖzeT}

AMAÇ: Subakut tiroidit (SAT) genellikle orta yaşlı kadınlarda mevsimsel geçiş dönemlerinde görülen, kendisine has trifazik seyri olan ağrılı ve inflamatuvar bir tiroid hastalığıdır. Bu yazımızda hastanemizde SAT tanısıyla takip ettiğimiz hastaların retrospektif analizini yaptık.

GEREÇ VE YÖNTEM: Hastanemizde Temmuz 2015-Mayıs 2019 yılları arasında SAT tanısı konulan hastaların klinik belirtileri, laboratuvar ve görüntüleme yöntemleri ve hastalık akıbetleri retrospektif olarak değerlendirildi.

BULGULAR: Yirmi dördü (\%19.4)'ü erkek, toplam 124 hasta analize dahil edildi. Hastaların yaş ortalaması 41.5 (min-maks: 20:73) yıl idi. Tiroid lojunda ağrı tüm hastalarda varken, bu belirtiyi \%45.9 sıklıkla ateş takip etti. Tanı esnasında tiroid stimülan hormon $0.02 \mathrm{mIU} / \mathrm{L}$ (0:0.63), serbest T4 $1.98 \mathrm{ng} / \mathrm{dL}$ (0.97:4.7), eritrosit sedimantasyon hizı $75.1 \pm 24.1 \mathrm{~mm} / \mathrm{saat}$ ve c-Reaktif Protein 62 mg/L (10.2:361) olarak bulundu. Tiroid uptake testi yapılan 123 hastadan 104 (\%83.9) hasta tiroid uptake testi düşük iken, 23 (\%18.6) hastanınki normal saptandı. Yüz dokuz (\%87.9) hasta non-steroidal antiinflamatuvar ilaç kullanmışken, 40 (\%32.3) hastada kısa süreli steroid kullanımı saptandı. Hastalığın takibinde 66 (53.2) hastada geçici hipotiroidi geliştiği ve L-tiroksin tedavisi başlandığı saptandı. Toplamda 27 (\%21.7) hastada kalıcı hipotiroidi saptandı.

SONUÇ: Subakut tiroiditli olgularımızın yaklaşık beşte birinde kalıcı hipotiroidi gelişti. Bizim kalıcı hipotiroid kabul ettiğimiz bazı olgularda L-tiroksin kullanım süresinin 1 yıldan kısa olması nedeniyle çalışmamızda bu düzeyde yüksek oranlarda kalıcı hipotiroidi saptamamıza sebep olmuş olabilir. Bu nedenle 1 yıl sonra aynı olguların yeniden analiz edilmesi uygun olacaktır.

Anahtar Kelimeler: subakut tiroidit, granülomatöz tiroidit, tiroidit

\section{ABSTRACT}

OBJECTIVE: Subacute thyroiditis (SAT) is a painful and inflammatory thyroid disease usually occurring in middle-aged women during seasonal transitions with triphasic course. We performed a retrospective analysis of patients followed-up in our hospital due to SAT.

MATERIALS AND METHODS: Clinical symptoms, findings of laboratory and imaging tests, and disease outcomes of patients with SAT between July 2015 and May 2019 were evaluated retrospectively.

RESULTS: Of 124 patients, 24 (19.4\%) men, were included. Patients' mean age was 41.5 (min-max: 20:73) years. While pain was present in the thyroid lodges of all patients, fever followed the pain with a frequency of $45.9 \%$. During the diagnosis, thyroid stimulating hormone, free T4, erythrocyte sedimentation rate and c-Reactive protein were found as 0.02 m/U/L (0:0.63), 1.98 $\mathrm{ng} / \mathrm{dL}$ (0.97:4.7), $75.1 \pm 24.1 \mathrm{~mm} / \mathrm{hour}$ and $62 \mathrm{mg} / \mathrm{L}$ (10.2:361), respectively. Of 123 patients undergoing the thyroid uptake test, while 104 (83.9\%) had lower rate of thyroid uptake, the uptake level of 23 (18.6\%) patients were within normal limits. During the follow-up, it was detected that 66 (53.2) patients developed transient hypothyroidism, and L-thyroxine treatment was started. In total, permanent hypothyroidism was detected in 27 (21.7\%) patients.

CONCLUSION: Approximately one fifth of our cases with SAT developed permanent hypothyroidism. Using L-thyroxine shorter than one year in some cases accepted as permanent hypothyroidism may have caused to detect permanent hypothyroidism cases at a higher rate in our study. Therefore, it will be appropriate to re-analyze the same cases after one year.

Keywords: subacute thyroiditis, granulomatous thyroiditis, thyroiditis

\section{Giriş}

Subakut tiroidit genellikle viral bir üst solunum yolu enfeksiyonu takiben ortaya çıkan, boyun ağrısı, tiroid lojunda rahatsızlık ve hassasiyet, ateş, diffüz guatr ile kendini gösteren inflamatuvar bir hastalık olup, sıklıkla mevsimsel geçiş dönemlerinde ve kadınlarda görülmektedir $(1,2,3)$. Hastalı̆ıı kendisine has trifazik bir seyri olup,

Yazışma Adresi/Address for Correspondence: Cevdet Duran, MD, Uşak Üniversitesi Tıp Fakültesi İç Hastalıkları Anabilim Dalı, Endokrinoloji ve Metabolizma Hastalıkları Bilim Dalı, 64200, Uşak/Türkiye

E-Posta/E-Mail: drcduran@gmail.com || Tel: +905334298585

Received/Geliş Tarihi: 22.06.2020 || Accepted/Kabul Tarihi: 21.07.020

Bu Eser Creative Commons Atıf-Gayriticari 4.0 Uluslararası Lisansı İle Lisanslanmıştır. This work is licensed under a Creative Commons

Attribution-NonCommercial 4.0 International License (CC BY-NC 4.0). 
başlangıçta 3-6 hafta süren hipertiroidisiz bir tirotoksikoz fazı, devamında ötiroidik faz, onun devamında yaklaşık \%30 olguda hipotiroidik faz ve en sonun da çoğu olguda ötiroidi ve iyileşme ile seyrederken bazı olgularda kalıc hipotiroidi gelişir (3). Hastalığın insidansı kadınlarda erkeklerden daha fazla olup (sırasıyla 19.1 olgu ve 4.1 olgu/100000/yıl) sıklığ yaş ile birlikte azalmaktadır (4). Subakut tiroidit gelişmiş olguların büyük çoğunluğu orta yaşlardaki kadın hastalardır (4). Ağrı SAT'ın en önemli karakteristiklerinden olup, olguların büyük çoğunluğunda sadece tiroid bölgesinde iken, bazı olgularda göğüs üst kesim, boyun, boğaz, çene kulak vb. yayılabilir. (3). Ağrı, tiroid lojunda hassasiyet ile beraber ateş, kırıklık, halsizlik ve yorgunluk sıklıkla bulunur. Ayrıca, hastalığın bulunduğu evresine göre tirotoksikoz ve hipotiroidi belirti ve bulguları da kliniğe eklenir (3). Tipik klinik ve muayene bulguları, laboratuvar analizleri ve radyoaktif iyot uptake testi ile (RAIU) ile tanı kolaylıkla konulabilir. Yine artmış serum tiroglobulin düzeyleri de tanıda yardımcı olabilir. Subakut tiroiditin tedavisi semptomatik olup, kesin bir tedavisi yoktur (3). Tirotoksikoz fazında tiroid hormon etkisini azaltmak için beta bloker ilaçlar; ateş ve ağrı için analjezik ve non-steroidal antiinflamatuvar ilaçlar (NSAii), bunlara yanıt alınamayan hastalarda kısa süreli steroid tedavisi kullanılabilir. Bütün bunlara ilaveten hipotiroidik fazda ise L-tiroksin replasmanı gerekir. Tedavide antitiroid ilaçların yeri yoktur. Olguların büyük çoğunluğunda kendiliğinden ötiroidi sağlanırken, bazı olgularda kalıcı hipotiroidi gelişir ve ötiroidi L-tiroksin ile başarılabilir.

Bu yazımızda Temmuz 2015-Mayıs 2019 tarihleri arasında hastanemizde SAT tanısı ile takip edilen hastaların klinik ve laboratuvar verilerinin retrospektif analizini sunduk.

\section{GEREÇ VE YÖNTEM}

$\mathrm{Bu}$ çalışma retrospektif dosya taraması şeklinde olup, çalışmaya Uşak Üniversitesi Eğitim ve Araştırma Hastanesi Endokrinoloji bölümünde Temmuz 2015-Mayıs 2019 tarihleri arasında subakut tiroid tanı konulan hasta listeleri hastane yazılım sisteminden tarandı. Çalışma öncesi yerel etik kuruldan çalışma ile ilgili onam alındı.

Hastane yazılım sisteminden subakut tiroidit tanısı konulan 135 hasta kaydı bulundu. Bunlardan 11 tanesinin hasta dosyasında klinik belirti yazmaması nedeniyle analize dahil edilmedi, hasta verilerine ulaşılan 124 tanesi analize dahil edildi. Hastaların yaş, cinsiyet, başvuru semptomları, tiroid stimülan hormon (TSH), serbest tiroksin (ST4), serbest triiyodotironin (ST3), eritrosit sedimantasyon hızı (ESR), cReaktif Protein (CRP) anti tiroglobulin (Anti Tg) ve anti tiroid peroksidaz (Anti TPO) antikorları, tiroid ultrasonografi (USG) sonuçları ve tiroid iyot uptake testi sonuçları, ayrıca tedavide kullanılan ilaçlar ve hastalık akıbeti hasta kartlarına işlendi. L-tiroksin tedavisi başlandıktan 6 ay sonra halen Ltiroksin tedavisine devam ediliyor olması kalıcı hipotiroidi olarak kabul edildi.

Bahsi geçen tarama süresi içerisinde hastanemizde TSH (N: 0.55-4.78 mIU/L), ST4: (N: 0.85-1.6 ng/dL), serbest T3 (N: 2.3$4.2 \mathrm{ng} / \mathrm{L})$, Anti TPO (0-57 U/mL) ve anti TG (0-40 U/mL) tetkikleri ElectroChemiLuminescence ImmunoAssay (ECLIA) yöntemi ile ADVIA Centaur XP (Siemens USA) cihazında, eritrosit sedimantasyon hızı (ESR) tetkiki (N: 0-20 mm) SISTAT ESR 20 kan sedimantasyon hızı analizörü cihazında infrared bariyer yöntemi ile (Sistat tanı ve tedavi sistemleri, Türkiye) ve CRP ( $\mathrm{N}: 0.1-5 \mathrm{mg} / \mathrm{L})$ düzeylerinin analizi ise Architect C 8000 (Abbott, USA) cihazında immünoturbidimetrik yöntem ile yapıldı.

Bu dönem içerisinde tiroid uptake ölçümü 185 MBq Tc99mperteknetatın intravenöz enjeksiyonunun uygulanmasından 20 dk. sonra çift başlıklı SPECT gama kamera (Siemens Symbia E Dual Head System, Siemens Medical Solutions USA Inc.) kullanılarak elde edildi. Enjeksiyondan önce ve sonra tiroid uptake'inin hesaplanması için dolu (DK) ve boş (BK) olarak 2 saniyelik enjektör görüntüleri alındı. Anterior projeksiyonda $128 \times 128$ matris boyutunda elde edilen tiroid görüntüsü üzerinden tiroid sınırları etrafından tiroid (TK) ve tiroid bezi sınırlarının dışından zemin aktivitesi (ZK) için iki ayrı ilgi alanı çizilerek sayımlar kaydedildi, güncel gama kameralarda mevcut yazılımlar ile otomatik olarak Tc-99m uptake yüzdesi $=($ TK-ZK) $/($ DK-BK $) \times \% 100$ formülü ile hesaplandı. Normal uptake aralığı \%0.3-3 kabul edildi.

\section{İstatiksel analiz}

Çalışma verilerinin normallik analizi Kolmogorov-Smirnov veya Shapiro-Wilk testleri ile yapıldı. Grup karşılaştırmalarında sürekli değişkenlerde normal dağılım gösterenlerde Student t-test, normal dağılmayanlarda Mann-Whitney-U testi uygulandı. Kesikli değişkenlerde ikili grup karşılaştırmalarında Fisher's Exact test, ikiden fazla grup karşılaştırmalarında Pearson Ki Kare Testi kullanıldı. Normal dağılım gösteren sürekli değişkenler ortalama \pm standart sapma, normal dağılım göstermeyen sürekli değişkenler ise ortanca (minimum: maksimum) olarak 
verildi. Sonuçların istatistiksel anlamlılığı \%95 güven aralığında değerlendirildi ve $p \leq 0.05$ anlamlı kabul edildi

\section{BULGULAR}

Yüz tanesi kadın, 24 (\%19.4)'ü erkek toplamda 124 hasta analize dahil edildi. Hastaların ortalama yaşı 41.5 (minmaks: 20:73) yıl olarak saptandı. Hastaların hepsinde boğaz ağrısı var iken, ateş 57 (\%45.9) hastada saptandı. Tanı esnasında hastaların TSH düzeyleri $0.02 \mathrm{mlU} / \mathrm{L}$ (0:0.63), serbest T4 düzeyleri $1.98 \mathrm{ng} / \mathrm{dL}$ (0.97:4.7), serbest T3 düzeyleri $4.43 \mathrm{ng} / \mathrm{L}$ (1.54:9.01), ESR düzeyleri 75.1 \pm 24.1 $\mathrm{mm} / \mathrm{saat}$ ve CRP düzeyleri $62 \mathrm{mg} / \mathrm{L}$ (10.2:361) bulundu (Tablo 1). 29 (\%23.4) hastada anti Tg pozitif iken, 11 (\%8.9) hastada anti TPO pozitifti, bu hastalardan $5(\% 4)$ 'inde ise her iki antikorda pozitifti.

Tablo 1. Hastaların bazı demografik ve laboratuvar verileri

\begin{tabular}{|c|c|c|c|c|}
\hline & $\begin{array}{l}\text { Toplam } \\
n=124\end{array}$ & $\begin{array}{l}\text { Kadın } \\
n=100\end{array}$ & $\begin{array}{l}\text { Erkek } \\
n=24\end{array}$ & $\begin{array}{l}p \\
\text { kadın vs } \\
\text { erkek }\end{array}$ \\
\hline Yaş & $\begin{array}{l}41.5(20: 73) \\
\text { yıl }\end{array}$ & $\begin{array}{l}41.5(20: 73) \\
\text { yıl }\end{array}$ & $41.5(35: 63)$ yıl & 0.232 \\
\hline TSH & $\begin{array}{l}0.02 \mathrm{mIU} / \mathrm{L} \\
(0: 0.63)\end{array}$ & $\begin{array}{l}0.02 \mathrm{mIU} / \mathrm{L} \\
(0: 0.63)\end{array}$ & $\begin{array}{l}0.01 \mathrm{mIU} / \mathrm{L} \\
(0: 0.45)\end{array}$ & 0.1 \\
\hline ST4 & $\begin{array}{l}1.98 \mathrm{ng} / \mathrm{dL} \\
(0.97: 4.7)\end{array}$ & $\begin{array}{l}1.96 \mathrm{ng} / \mathrm{dL} \\
(0.97: 4.7)\end{array}$ & $\begin{array}{l}1.98 \mathrm{ng} / \mathrm{dL} \\
(1.09: 4.3)\end{array}$ & 0.842 \\
\hline ST3 & $\begin{array}{l}4.43 \mathrm{ng} / \mathrm{L} \\
(1.54: 9.01)\end{array}$ & $\begin{array}{l}4.29 \mathrm{ng} / \mathrm{L} \\
(1.54: 9.01)\end{array}$ & $\begin{array}{l}4.71 \mathrm{ng} / \mathrm{L} \\
(2.83: 8.4)\end{array}$ & 0.238 \\
\hline ESR & $75.1 \pm 24.1$ & $75.5 \pm 20$ & $73.1 \pm 19.9$ & 0.656 \\
\hline CRP & $\begin{array}{l}62 \mathrm{mg} / \mathrm{L} \\
(10.2: 361)\end{array}$ & $\begin{array}{l}61.6 \mathrm{mg} / \mathrm{L} \\
10.2: 361)\end{array}$ & $\begin{array}{l}62.3 \\
\mathrm{mg} / \mathrm{L}(16.6: 177.4)\end{array}$ & 0.693 \\
\hline
\end{tabular}

TSH: Tiroid stimülan hormon, ST4: serbest tiroksin, ST3: serbest triiyodotironin, ESR: eritrosit sedimantasyon hızı, CRP: c-Reaktif Protein,

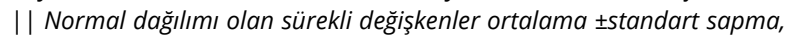
normal dağılımı olmayan sürekli değişkenler ise ortanca (minimum: maksimum) olarak verilmiştir.

Hastalar cinsiyete göre yeniden analiz edildiğinde kadın ve erkelerde yaş, TSH, serbest T4, serbest T3, CRP ve ESR düzeyleri benzerdi (Tablo 1). Tiroid iyot uptake testi yapılan 123 hastadan 104 (\%83.9) hasta tiroid uptake testi düşük iken, 23 (\%18.6) hastanın ki normal saptandı, 1 hastaya ise uptake bakılmamıştı.

Yüz dokuz (\%87.9) hasta non-steroidal antiinflamatuvar ilaç kullanırken, 39 (\%32.3) hastada kısa süreli steroid kullanıldığı saptandı. Tüm hastalarda tiroid ultrasonografisi (USG) tiroiditle uyumlu olarak heterojen idi, 38 (\%30.6) hastada tiroidite ilaveten nodüler guatr olarak da raporlandı. Rekürrens veya migratuvar tiroidit 19 (\%15.3) hastada saptandı.

Hastalığın takibinde 66 (\%53.2) hastada geçici hipotiroidi geliştiği ve L-tiroksin tedavisi başlandığı saptandı. Toplamda 27 (\%21.7) hastada kalıcı hipotiroidi saptandı. Kalıcı hipotiroidi gelişen 27 hastanın 22'si (kalıcı hipotiroidi gelişenlerin \%81.5'i) kadındı. Steroid tedavisi alan 40 hastanın 7 (\%17.5)'sinde kalıcı hipotiroidi gelişmişken, steroid almayan 82 hastadan 20 (\%24.4)'sinde kalıc hipotiroidi gelişti $(p=0.389) .19$ hastada (\%15.3) hastada nüks veya gezici SAT saptandı.

\section{TARTIŞMA}

Bu çalışmada 2015-2019 yılları arasında SAT tanısı ile tanı konulup takip ve tedavi edilen 124 hastayı sunduk.

Subakut tiroidit genelde orta yaşı kadınlarda görülen inflamatuvar bir tiroid hastalığı olup, sıklığı kadınlarda erkelerde 4-5 kat daha fazladır $(3,5)$. Erdem ve ark. ülkemizden yapmış oldukları çalışmalarında olguların yaş ortalamasının 34ะ17.8 yıl olduğunu ve olguların \%79.3'ünün kadın olduğunu bildirmişlerdir (5). Bizim çalışmamızda kadınların oranı \%80.6 olup, hastaların yaş ortalaması 41.5 yıl idi. En genç hastamız 20 yaşında iken en yaşlısı 73 yaşında idi.

Ağrı ve ateş SAT'ın en önemli karakteristiklerindendir (3). Subakut tiroidite ani veya yavaş başlangıçlı, boyun, boğaz, göğüs üst, çene, kulak kesimine yayılabilen ağrı görülür. Ağrı ile beraber tiroid lojunda hassasiyet ve rahatsızlık hissi olup, gerek muayene gerekse ultrasonografi gibi işlemleri güçleştirebilir. Erdem ve ark. yapmış olduğu yüz yetmiş altı hastayı içeren ülkemizden bir çalışmada, ağrı SAT'ı kadınlarda \%97.1 erkeklerde ise \%100 sıklıkla bildirilmişken ateş \%46.2'sinde bildirilmiştir (5). Bizim çalışmamızda olguların tamamında boyunda tiroid bölgesinde ağıı vardı. Ateş \%45.9 hastada saptandı ve önceki çalışmalar ile uyumlu idi.

Subakut tiroiditin tedavisi semptomatik olup, kesin bir tedavisi yoktur. Olguların yaklaşık yarısında tirotoksik faz görülür. Bu fazda tiroid bezi destrüksiyonuna bağlı kanda tiroid hormonları yükselir. Tiroid iyot uptake testi yapıldığında bu fazda uptake düşük bulunur (3). Bizim çalışmamızda hastaların \%18.6'sında uptake normal saptandı. Uptake testi normal olan hastalar tekrar değerlendirildiğinde klinik ve diğer laboratuvar parametreleri SAT ile uyumlu idi. Ancak bu hastaların hastaneye bize geç başvurması veya bazı hastalara uptake için ileri tarihe randevu verilmesi gibi sebeplerden dolayı sürenin uzaması ve hastalığın iyileşme dönemine girmesi sonucu uptake normal çıkmış olabilir (6). Subakut tiroidit seyrinde hipertiroidisiz tirotoksikoz olduğu için tedavide 
antitiroid ilaçların yeri yoktur. Bu aşamada tiroid hormonunun periferik dokularda etkisini azaltmak için beta-blokerler ilaçlar kullanılabilir (3). Yine hastalarda var olan ateş ve ağrı için analjezik ve antiinflamatuvar ilaçlar kullanılabilir (3). Bunlara yanıt alınamayan hastalarda kısa süreli steroid tedavisi verilebilir. Bu 3-6 haftalık tirotoksikoz döneminden sonra inflamasyonda azalma meydana gelir ve gerek şikayetler gerek ise CRP, ESR gibi inflamasyon göstergeleri düşüşe geçer. Hastalık seyrinde kendiliğinden ötiroidi geliştikten sonra devam eden aşamada \%30 olguda geçici hipotiroidi gelişir. $\mathrm{Bu}$ aşamada hastada tirotoksikozun, ayrıca da ağrı, ateş gibi inflamasyonun belirti ve bulguları kaybolur ve bunun yerini hipotiroidiye bağlı belirti ve bulgular alır. Bazı hastalarda tirotoksikoz fazında tekrarlanma, inflamatuvar göstergelerde yeniden artış olabilir veya hastalık önceden tek lobu tutmuş iken bir süre sonra diğer lobda da tekrarlayabilir. Hipotiroidik fazda tedavide ise L-tiroksin replasmanı gerekir. Hipotiroidik faz 3-6 ay arasında sürer ve olguların çoğunda kendiliğinden iyileşebilir. Olguların büyük çoğunluğunda kendiliğinden ötiroidi sağlanırken, az bir kısmında kalıcı hipotiroidi gelişir ve ömür boyu L-tiroksin gereksinimi ortaya çıkabilir. Bizim çalışmamızda tirotoksikoz fazında tüm hastalar beta-bloker aldı. Ateşi düşürmek, ağrı ve inflamasyonu baskılama için 109 hastaya (\%87.9) NSAii verildiği, NSAii'nin yeterli olmadığı 40 (\%32.3) hastada ise steroid tedavisi kullanıldığı saptandı. Çalışmamızda hastaların \%53.2'inde geçici hipotiroidi geliştiğini ve L-tiroksin tedavisi başlandığı, kalıcı hipotiroidi gelişen hasta sıklığını ise \%21.7 olarak bulduk. Literatürde bazı çalışmalarda kalıcı hipotiroidi sıklığı \%5-15 arasında bildirilmiştir. Fatourechi ve ark. yapmış olduğu 1960 ile 1997 yılları arasında 160 SAT'ı hastanın izlendiği çalışmalarında, kalıcı hipotiroidi sıklığını \%15 olarak bildirmişlerdir (4). Başka bir çalışmada Lio ve ark. kalıcı hipotiroidi sıklığını \%5 olarak bildirmişlerdir (7). Bizim çalışmamızda kalıcı hipotiroidi oranı diğer çalışmalardan yüksek saptandı. Amerikan Tiroid Cemiyeti kılavuzunda Ltiroksin tedavisini ilacın başlangıcından 3-6 ay gibi sonraki bir süre içinde azaltılarak kesilmesi ve tiroid hormon yanıtının değerlendirilmesini önermektedir (3). Her ne kadar kalıcı hipotiroidi demek için 6 aydan uzun süre gerekse de bazı olguların 1 yıl civarında ötiroidik hale gelmesi $(4,8)$ ve bizim çalışmamızda bazı olguların takiplerinin 1 yıldan az olması nedeniyle kalıcı hipotiroidi oranımız yüksek çıkmış olabilir.
Fatourechi ve ark. yapmış olduğu bir çalışmada SAT tanısıyla steroid alan hastaların yaklaşık \%25 inde kalıcı hipotiroidi gelişmişken almayan hasta grubunda bu oran \%10 olarak $(p<0.005)$ olarak bildirilmiştir (4). Bizim çalışmamızda steroid alan ve almayan hastalarda kalıc hipotiroidi oranı benzerdi.

Subakut tiroidit tipik USG görünümü fokal veya multifokal, sınırları tam seçilemeyen hipoekoik alanlar olup, malignite ile karışabilmektedir (9). Ancak hastalık seyrinde bazı hastalarda zamanla bu lezyonların boyutları değişebilmekte, hatta kaybolabilmektedir. Bizim çalışmamızda ultrasonografi raporlarının \%30.6'sında tiroitte nodülden bahsediliyordu. Ancak SAT esnasında gelişen inflamasyona bağlı değişiklikler sonografik olarak gerçek nodülü taklit edebilir $(9,10)$. Bizim çalışmamızın bir kısıtlayıcı tarafı bu dönem içerisinde yapılan tiroid USG'ler farklı cihaz ve farklı hekimler tarafından yapılmış olması idi. Ultrason sonuçlarının raporlanması değerlendirmeyi yapan hekimler arasında oldukça farklııı gösterebilir. Bu nedenle çalışmamızda nodüllerin kontrol sonografik takibi analize dahil edilmedi. Ayrıca ince iğne biyopsisi yapılıp yapılmadığ ve yapıldı ise sonuçlarını analize dahil etmememiz diğer bir kısıtlayıcı neden idi.

Hastalarımızda rekürrens veya migratuvar tiroidit 19 hastada (\%15.3) saptandı. Erten ve ark. NSAii alan kadınların \%10, erkeklerin \%12'sinde rekürrens olduğunu bildirmişlerdir (4). Subakut tiroiditli hastaların yaklaşık \%25 kadarında tiroid otoantikor pozitifliği saptanmıştır $(5,8)$. Bizim çalışmamızda olguların \%23.4'ünde anti Tg pozitif iken, \%8.9 unda anti TPO pozitifti.

Çalışmamızda bir gebede, gebeliğinin 6. hastasında SAT saptandı. Parasetamol tedavisi alan hasta gebeliğinin 21 haftasında erken membran rüptürü nedeniyle ölü doğum yaptı. Literatürde gebelik seyrinde SAT sınırlı sayıda olguda bildirilmiş olup, bildirilen olgularda SAT'ın gebelik sonuçları üzerine olumsuz etkisi saptanmamıştır $(11,12)$.

Sonuç olarak SAT hastalarımız analiz edildiğinde kalıcı hipotiroidi gelişme sıklığı dışındaki bulgularımız önceki çalışmalara benzerdi. Ancak olgularımızın yaklaşık beşte birinde kalıcı hipotiroidi gelişti ve bu önceki çalışmalardan daha yükse idi. Bazı yazarlar SAT'lı olgularda kalıcı hipotiroidi demek için 1 yıldan uzun süre L-tiroksin kullanımını kabul etmiştir. Bizim kalıcı hipotiroidi kabul ettiğimiz bazı olgularda L-tiroksin kullanım süresinin 1 yıldan kısa olması nedeniyle çalışmamızda bu düzeyde 
yüksek oranlarda kalıcı hipotiroidi saptamamıza sebep olmuş olabilir. Bu nedenle çalışmamıza dahil edilen olguların 1 yıl sonra yeniden analiz edilmesi uygun olacaktır.

\section{AÇIKLAMA}

Analize dahil edilen bir olgu "Gebelik seyrinde subakut tiroidit: Olgu sunumu" başlığıyla Olgu Sunumu olarak yayın açısından değerlendirilmek üzere Ege Tıp Bilimleri Dergisi'ne yollanmıştır.

Etik: Bu çalışmanın etik kurulu alınmıştır.

Ethics committee approval had been taken.

Yazar katkı durumu; Çalışmanın konsepti; ZAU, CD, dizaynı; $C D$, Literatür taraması; $C A, C D$, verilerin toplanması ve işlenmesi; ZAU, CA, istatistik; $C D$, yazım aşaması; CA CD

Author contribution status; The concept of the study; ZAU, CD, design; $C D$, literature review; $C A, C D$, collecting and processing data; ZAU, CA, statistics; $C D$, writing phase; $C A C D$

Yazarlar arasında çıkar çatışması yoktur.

The author declares no conflict of interest.

Finansal Destek: yoktur / Funding: none

doi: https://doi.org/10.33713/egetbd.756260
Transitory subclinical and permanent hypothyroidism in the course of subacute thyroiditis (de Quervain). Acta Endocrinol (Copenh). 1984;106:67-70.

8. Benbassat CA, Olchovsky D, Tsvetov G, Shimon I. Subacute thyroiditis: clinical characteristics and treatment outcome in fifty-six consecutive patients diagnosed between 1999 and 2005. J Endocrinol Invest. 2007;30:631-635.

9. Park HK, Kim DW, Lee YJ. Suspicious sonographic and cytological findings in patients with subacute thyroiditis: two case reports. Diagn Cytopathol 2015;43:399-402.

10. Lee YJ, Kim DW. Sonographic characteristics and interval changes of subacute thyroiditis J Ultrasound Med. 2016;35:1653-1659.

11. Anastasilakis AD, Karanicola V, Kourtis A, et al. A case report of subacute thyroiditis during pregnancy: Difficulties in differential diagnosis and changes in cytokine levels. Gynecol Endocrinol. 2011;27:384-390

12. Hiraiwa $T$, Kubota $S$, Imagawa $A$, et al. Two cases of subacute thyroiditis presenting in pregnancy. J Endocrinol Invest. 2006;29:924-927

\section{KAYNAKLAR}

1. Lazarus JH. Silent thyroiditis and subacute thyroiditis. In: The Thyroid: A Fundamental and Clinical Text, 7th Ed, Braverman LE, Utiger RD (Eds), Lippincott Williams \& Wilkins, Philadelphia 1996. p.577.

2. Volpé R. The management of subacute (DeQuervain's) thyroiditis. Thyroid. 1993;3:253-255.

3. Ross DS, Burch HB, Cooper DS, et al. 2016 American Thyroid Association Guidelines for Diagnosis and Management of Hyperthyroidism and Other Causes of Thyrotoxicosis Thyroid. 2016;26:1343-1421

4. Fatourechi V, Aniszewski JP, Fatourechi GZE, Atkinson EJ, Jacobsen SJ. Clinical Features and Outcome of Subacute Thyroiditis in an Incidence Cohort: Olmsted County, Minnesota, Study, J Clin Endocrinol Metab. 2003;88:2100-2105

5. Erdem N, Erdogan M, Ozbek M, et al. Demographic and clinical features of patients with subacute thyroiditis: results of 169 patients from a single university center in Turkey. J Endocrinol Invest. 2007;30:546-550

6. Kamio N, Kobayashi I, Mori M, Uehara T, Fukuda H. Permissive role of thyrotropin on thyroid radioiodine uptake during the recovery phase of subacute thyroiditis. Metabolism. 1977;26:295-299.

7. Lio S, Pontecorvi A, Caruso M, Monaco F, D'Armiento M. 